\title{
Fatigue life prediction of titanium alloy for block loading using the hybrid approach of critical plane and continuum damage mechanics
}

\author{
M. Kamal ${ }^{1}$ and M.M. Rahman ${ }^{2}$ \\ ${ }^{1}$ International Affairs and training Division \\ Pakistan Atomic Energy Commission, Karachi, Pakistan \\ ${ }^{2}$ Automotive Engineering Research Group \\ Faculty of Mechanical Engineering, Universiti Malaysia Pahang, \\ 26600 Pekan, Pahang, Malaysia \\ Email: mustafizur@ump.edu.my \\ Phone: +6094246239; Fax: +6094246222
}

\begin{abstract}
The present study is related to the performance analysis of the newly proposed fatigue estimation model for titanium alloy BT9 against block loading. Lately, research efforts have been concentrated on developing the capability to handle complex multiaxial loading conditions for fatigue estimation. The current study is focused on testing the proposed hybrid approach involving the critical plane and continuum damage mechanics. The calibration of the proposed model is done by determining the model coefficients by using a genetic algorithm. Experimental fatigue lives for titanium alloy BT9 with block loading consisting of axial, torsion and out-of-phase axial-torsion loading segments are considered to analyse the accuracy of the proposed model. The proposed model is validated by using finite element analysis to estimate fatigue life for titanium alloy BT9. Simplifications were assumed to handle the block loads, and axial, torsion and out-ofphase loading conditions were used for calibration. The estimated fatigue life results show good agreement with published results for block loads.
\end{abstract}

Keywords: Multiaxial fatigue; critical plane method; continuum mechanics; genetic algorithm; titanium alloy BT9.

\section{INTRODUCTION}

Fatigue life has been a major factor in mechanical design since the experiments performed by Wohler $[1,2]$. Numerous research efforts have been made to safely assess the fatigue life of mechanical components under time-variable loadings [3-5]. Fatigue life prediction in real components is a complex process having a number of variables to deal with to avoid unwanted and critical failures [6-11]. The reliability of any fatigue life assessment technique depends on factors such as stress concentration, degree of multiaxiality in the stress field, and the ability to model the damage caused by non-zero superimposed static stresses [12]. To maintain the accuracy with real life data, the calibration of such an engineering fatigue assessment method should be based on pieces of experimental information that can be easily obtained through tests run in accordance with the pertinent standard codes [6, 12-15]. The stress analysis is conducted to correctly estimate fatigue damage by directly post-processing simple linear elastic finite element models [16]. Multiaxial loads, which can be proportional or non-proportional, are common for many 
components and structures [17-23]. Even under uniaxial loads, multiaxial stresses often exist, although typically in-phase, due to geometric constraints at notches. Such multiaxial loads and stress states are frequently encountered in many industries, including automotive, aerospace, and power generation, among others [5, 17, 24]. Research to develop new fatigue estimation models is continuously underway, but a general purpose model has still not been developed for the wide-ranging description of fatigue phenomena [4, 25-28]. This study is related to testing the performance of the new fatigue life estimation model based on a genetic algorithm in conjunction with the critical plane method and continuum damage mechanics. Theory is proposed by means of evolution equations, i.e. incremental damage relations and not changes or damage per cycle. The continuum theory contains in itself damage accumulation during arbitrary load histories and it thereby avoids cycle counting techniques [29]. As stated in the literature, if the fatigue life assessment is to be performed under real loading conditions, long random time histories are used. Then the application of cycle counting methods leads to an overcomplicated lengthy solution, which cannot be applied in practical engineering analysis [30]. In order to develop an expression defining the proposed fatigue parameter, the stress-strain parameters needed to determine the state of the material under load are identified from models already published in the literature. Strain-based models are considered for this study as they are more robust in capturing high cycle fatigue and also low cycle fatigue where plasticity may occur [31].

Fatemi and Socie [32], based on the work of Brown and Miller, proposed to replace the normal strain term by the normal stress, as shown in Eq. (1). They argued that mean stress and non-proportional hardening effects can be captured by using normal stress. Critical plane models that include only strain terms cannot reflect the effect of mean stress or strain path dependent hardening.

$$
\frac{\Delta \gamma}{2}\left(1+k \frac{\sigma_{n, \max }}{\sigma_{y}}\right)=\frac{\tau_{f}^{\prime}}{G}\left(2 N_{f}\right)^{b \gamma}+\gamma_{f}^{\prime}\left(2 N_{f}\right)^{c \gamma}
$$

where $\Delta \gamma$ is the shear strain range, $\sigma_{\mathrm{n}, \max }$ is the normal shear stress on the plane from planes having maximum $\Delta \gamma, \mathrm{k}$ is a material sensitivity factor, $\sigma_{\mathrm{y}}$ is yield strength, $\mathrm{N}_{\mathrm{f}}$ is fatigue life, $\tau_{\mathrm{f}}, \gamma_{\mathrm{f}}, \mathrm{G}, \mathrm{b}_{\gamma}, \mathrm{c}_{\gamma}$ are material properties having their usual meanings.

Wang and Brown [33] have proposed a modification of the model proposed by [34], adding the capability to handle the strain path effect. The model is expressed in Eq. (2).

$$
\frac{\Delta \hat{\gamma}}{2}=\frac{\Delta \gamma_{\max }}{2}+S \varepsilon_{n}^{*}=\left(1+v_{e}+\left(1-v_{e}\right) S\right) \sigma_{f}^{\prime}\left(2 N_{f}\right)^{b}+\left(1+v_{p}+\left(1-v_{p}\right) S\right) \varepsilon_{f}^{\prime}\left(2 N_{f}\right)^{c}
$$

where $\Delta \hat{\gamma}=$ equivalent shear strain connection, $\Delta \gamma_{\max }=$ maximum shear strain range, $\varepsilon n^{*}=$ normal strain excursion between two turning points of $\gamma_{\max }, v_{\mathrm{e}}$ and $v_{\mathrm{p}}=$ elastic and plastic Poisson ratio, $S=$ material parameter representing the influence of normal strain on fatigue crack growth.

Smithet al. [35], revisited by Ince and Glinka [36], proposed a fatigue model for materials that primarily fail by crack growth on the planes of maximum tensile strain and stress. The proposed relationship includes both the cyclic strain range and the maximum stress as expressed in Eq. (3). For multiaxial loading, the SWT parameter is based on principal 
strain range $\Delta \varepsilon_{1}$, and the maximum stress on principal strain range plane, $\sigma_{\mathrm{n}, \max }$. The stress term is used to describe multiaxial loading and non-proportional hardening effects.

$$
\sigma_{n, \max } \frac{\Delta \varepsilon_{1}}{2}=\frac{\sigma_{f}^{\prime 2}}{E}\left(2 N_{f}\right)^{2 b}+\sigma_{f}^{\prime} \varepsilon_{f}^{\prime}\left(2 N_{f}\right)^{p+c}
$$

Liet al. [37], Liet al. [38] presented a simple critical plane type method to assess the fatigue life of metallic materials subjected to proportional and non-proportional loading. The model has the maximum shear strain range, normal strain range and the maximum normal stress on the maximum shear strain range plane (Eq. (4)).

$$
\frac{\Delta \varepsilon_{e q}^{*}}{2}=\frac{\Delta \gamma_{\max }}{2}+\left(1+\frac{\sigma_{n, \text { max }}}{\sigma_{y}}\right) \frac{\Delta \varepsilon_{n}}{2}
$$

Shanget al. [39] have proposed a damage parameter based on the critical plane, having the maximum shear strain and a higher value of normal strain excursion, as expressed in Eq. (5). The proposed parameter shows good correlation with the multiaxial fatigue lives of different materials in low cycle loading cases.

$$
\left(\varepsilon_{n}^{*^{2}}+\frac{v_{e f f}\left(2-v_{e f f}\right)}{\left(1+v_{e f f}\right)^{2}}\left(\frac{\Delta \gamma_{\max }}{2}\right)^{2}\right)^{1 / 2}=\frac{\sigma_{f}^{\prime}}{E}\left(2 N_{f}\right)^{b}+\varepsilon_{f}^{\prime}\left(2 N_{f}\right)^{c}
$$

Ince and Glinka [40] have proposed two different forms of fatigue damage parameter related to the maximum fatigue damage plane. The two forms are called the generalized strain energy damage parameter $\left(W_{\text {gen }}^{*}\right)$, expressed in Eq. (6), and the generalized strain amplitude damage parameter $\left(\Delta \varepsilon_{g e n}{ }^{*}\right)$, expressed in Eq. (7).

$$
\begin{gathered}
W_{\text {gen }}^{*}=\left(\tau_{\max } \frac{\Delta \gamma^{e}}{2}+\frac{\Delta \tau}{2} \frac{\Delta \gamma^{p}}{2}+\sigma \quad \frac{\Delta \varepsilon_{n}^{e}}{2}+\frac{\Delta \sigma_{n}}{2} \frac{\Delta \varepsilon_{n}^{p}}{2}\right)_{\max }=f\left(N_{f}\right) \\
\frac{\Delta \varepsilon_{\text {gen }}^{*}}{2}=\left(\frac{\tau_{\max }}{\Delta \tau / 2} \frac{\Delta \gamma^{e}}{2}+\frac{\Delta \gamma^{p}}{2}+\frac{\sigma_{n, \max }}{\Delta \sigma_{n} / 2} \frac{\Delta \varepsilon_{n}^{e}}{2}+\frac{\Delta \varepsilon_{n}^{p}}{2}\right)_{\max }=f\left(N_{f}\right)
\end{gathered}
$$

As per study of the above mentioned models, the normal $(\Delta \varepsilon)$ and shear $(\Delta \gamma)$ strain ranges are identified so that plasticity induced during the applied loading can be captured. Mean stress effects and material hardening behaviour are included for fatigue life estimation through the maximum and mean normal and shear stresses $\left(\sigma_{\max }, \tau_{\max }, \sigma_{\mathrm{m}}, \tau_{\mathrm{m}}\right)$. The newly proposed model is studied against blocks of axial, torsion and out-of-phase axial-torsion load segments on a tubular specimen.

\section{METHODS AND MATERIALS}

\section{Proposed Multiaxial Damage Parameter}

Fatigue failure can be defined as the result of a complex interaction of variable multiaxial loads and time [2]. Failure is defined as the nucleation of a crack and crack propagation to final failure, which can occur at one or more points of the structural component up to the final collapse [6]. Cracks initiate on the local shear plane at or adjacent to stress 
concentrations, such as persistent slip bands, inclusions, porosity, or discontinuities. Once nucleation occurs and cyclic loading continues, the crack tends to grow along the plane of maximum shear stress and through the grain boundary [1]. In the present model, failure is assumed to occur with the start of crack nucleation, and the orientation of the crack is on a plane known as the critical plane, which is identified according to the considered criterion. The criterion for critical planes identification is the plane having the maximum value of the fatigue parameter. The proposed evolution equations for the newly proposed model are formulated as one equation defining the damage criterion parameter ' $\mathrm{P}$ ' (Eq. (8)), expressed in terms of strain ranges $(\Delta \gamma, \Delta \varepsilon)$, maximum shear and maximum normal stresses $\left(\tau_{\max }, \sigma_{\mathrm{n}, \max }\right)$ determined on the critical plane.

$$
P=a_{1}\left(\Delta \gamma \cdot \tau_{\max }\right)+a_{2}\left(\Delta \varepsilon \cdot \sigma_{n, \max }\right)-\frac{\sigma_{L}^{2}}{E}-e v
$$

where $\mathrm{a}_{1}, \mathrm{a}_{2}$ and $\sigma_{\mathrm{L}}$ are material constants determined by calibrating the model against a known fatigue life and load history.

Parameter $e v$ (Eq. (8)) defines the change in parameter P with stress history and is related to the concept of isotropic and kinematic hardening of materials. The parameter is defined with the criterion that if during a load step $\mathrm{D}>0$, then $e v$ is defined by Eq. (9) and if $\mathrm{D}<0$, then ev for that step is zero $(e v=0)$, which means that there is no modification in parameter $\mathrm{P}$ during that load step by $e v$.

$$
e v=V . d P^{m}\left(\frac{\tau_{\max }-\tau_{m}}{E}\right)\left(\frac{\sigma_{\max }-\sigma_{m}}{E}\right)
$$

where $\mathrm{V}$ is a material parameter and $\mathrm{m}$ is the power of the increment of parameter $\mathrm{P}$.

The expression relating damage $\mathrm{D}_{\mathrm{n}}$ for each load step with damage parameter $\mathrm{P}$ and $\Delta \mathrm{P}$, i.e. change in $P$ with each load step, is shown in Eq. (10), where $K$ and $R$ are material parameters.

$$
D_{n}=K \cdot P^{R} . \Delta P
$$

Damage is accumulated at a monitored location most susceptible to fatigue failure, and the stress-strain state at each load step is evaluated with respect to mathematical function $P$ (Eq. (8)). A certain load step where the stress-strain state results in a value of P less than zero $(\mathrm{P} \leq 0)$ will not result in damage to the material. In other words, a damage increment will occur only when the stress-strain state leads to $\mathrm{P}>1$. Additionally, for a damage increment to occur, the change in parameter $\mathrm{P}$ should be positive $(\Delta \mathrm{P}>0)$, i.e. the value of $\mathrm{P}$ should be increased in the current load step from the previous one to consider any damage to occur in the current load step. The total damage $\mathrm{D}$ at the point of the component under study is evaluated as the accumulated function of damage increments $D_{n}$ at each load step, so at each load step of the fatigue process, the damage increment is equal to or greater than zero, i.e. $\mathrm{D}_{\mathrm{n}}$, and consequently the material damage $\mathrm{D}$ is a nondecreasing positive function during the load history [29]. Complete damage will occur when $D$ reaches unity $(D=1)$. Figure 1 shows the flow chart of the fatigue life estimation process by the calibrated proposed model. 


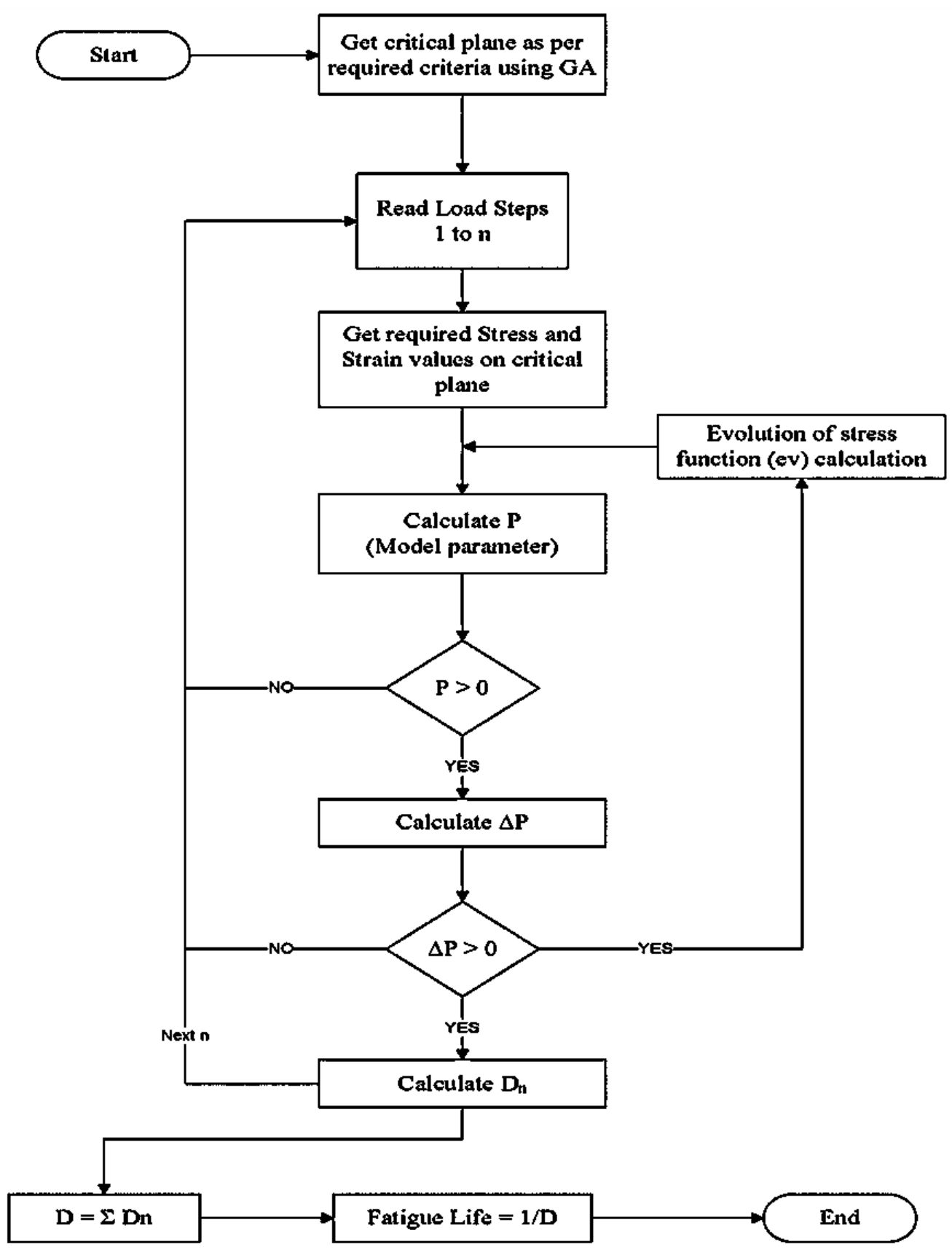

Figure 1. Fatigue life estimation process flow chart for proposed model.

\section{Model Calibration using Genetic Algorithm}

The proposed model can be used to estimate fatigue life if all the parameters are calibrated according to a known load and fatigue life. In the present section, a genetic algorithm (MOGA-II) is used to calibrate the model parameters $\left(a_{1}, a_{2}, \sigma_{L}, V, m, K, R\right)$. GAs have advantages with respect to classical techniques, as they allow us to handle problems with multiple minima and non-convexity properties, thus avoiding numerical instability and the missing of the global optimum [41]. A GA operates by simulating a natural evolution process of life [42]. These algorithms are used to minimize or maximize an objective function chosen to solve a given problem. 


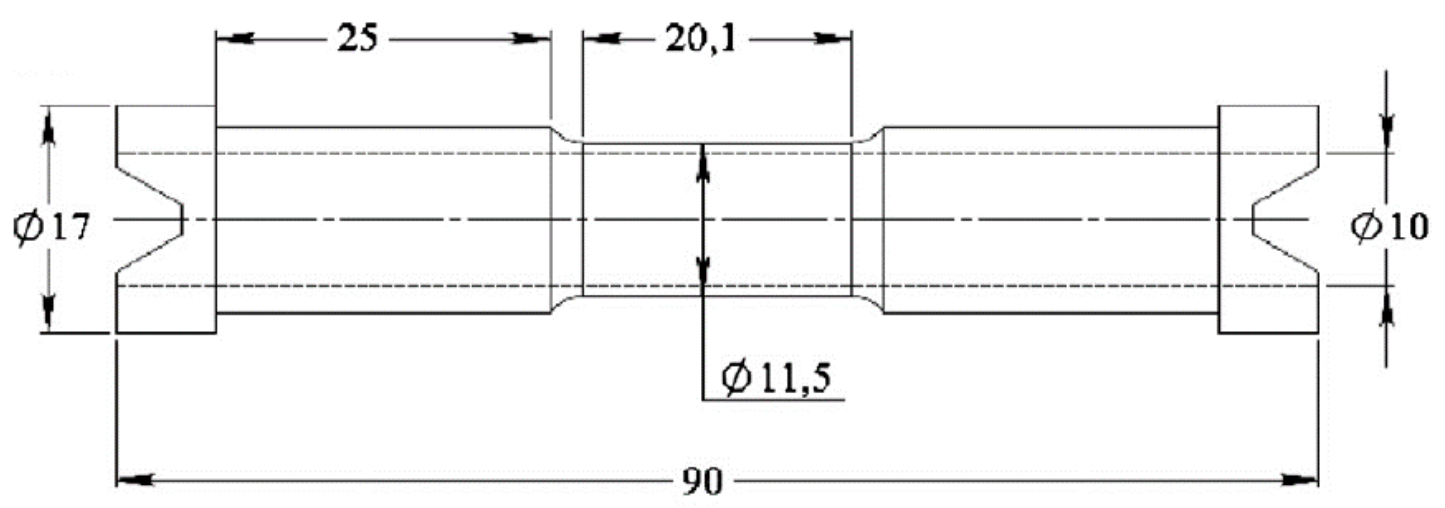

(a) Geometry detail (all dimensions in $\mathrm{mm}$ ).

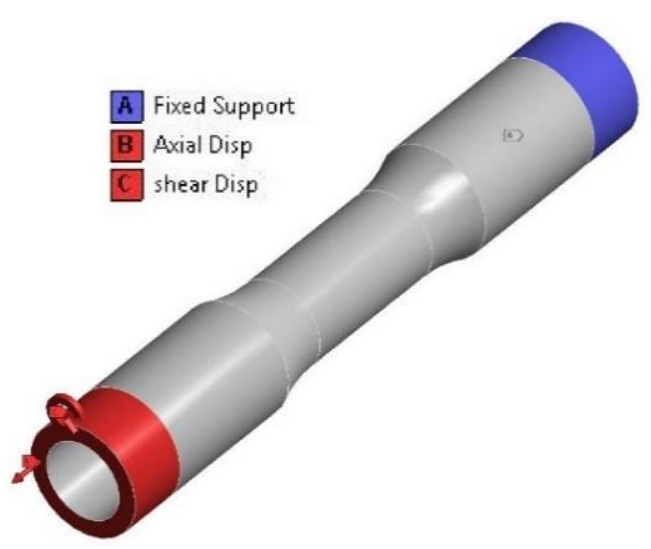

(b) Loading and constraints

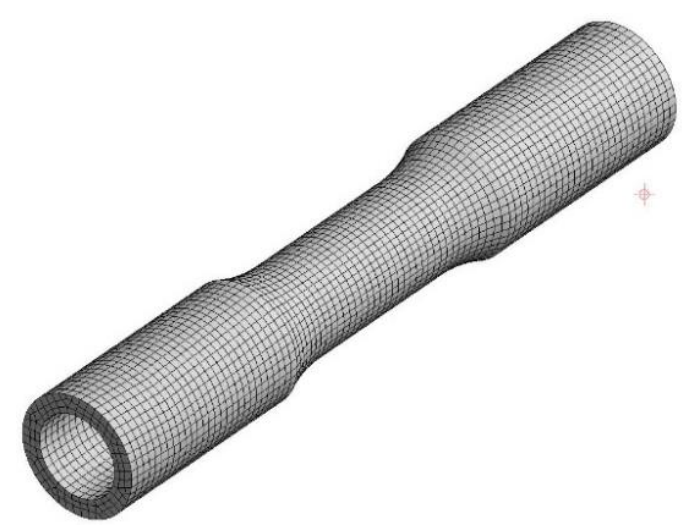

(c) Finite element model

Figure 2. Geometry detail of titanium alloy BT9 specimen.

This method can be used to optimize model parameters according to the known loading with the fatigue life for the applied loading $[43,44]$. The advantage of using a GA for the proposed model is that GAs can handle any kind of objective function and can handle large population sets. They use basic concepts like random number generation, choice, switch and combinations of such generated numbers to get a new population which has better performance than the previous generation [45]. This process is repeated iteratively until the required tolerance is achieved and thus the optimal condition can be achieved [46]. In the present study, the objective function is defined as damage prediction error, err:

$$
\text { err }=\mathrm{D}-\mathrm{D}_{\mathrm{FL}}
$$

where $\mathrm{D}$ is the total cumulative damage after each load step and $\mathrm{D}_{\mathrm{FL}}$ is the inverse of fatigue life at a known loading which is being used for calibration. The values of the model parameters used for characterization of the damage mechanics approach are now determined by minimizing the objective function err using the GA procedure [47].

\section{Finite Element Modelling}

Finite element analysis of the specimen geometry used in experimental fatigue life determination of titanium alloy BT9 published in the literature [48] is performed to determine the stress-strain response for the applied load blocks. The geometry of the 
specimen is shown in Figure 2(a) and the material properties of titanium alloy BT9 are given in Table 1. The finite element model is developed utilizing the ANSYS software with 20-node hexahedral elements [7, 49]. Axial and shear strains are applied such as to generate experimentally noted axial and shear strain at the gauge length, as shown in Figure 2(b). Hex mesh using the seep method is shown in Figure 2(c). As plastic deformation has to be considered, a non-linear analysis is performed including a full stress-strain curve in the material model of the titanium alloy BT9. The details of the applied loads and respective fatigue life taken from the literature [48] are reported in Table 2 and Table 3, and the load blocks are shown in Figure 3. The centre of the gauge length is considered to be the critical point for crack initiation and, to predict the fatigue life as close to the experimental values as possible, the state of stress and strain at the surface of the specimen is used in the estimation of the fatigue life.

\section{RESULTS AND DISCUSSION}

\section{Mesh Independence Study}

To find the mesh size for the optimum performance between accuracy, solution time and storage of result files, a mesh independence study has been performed [50, 51]. Maximum principal, von Mises and Tresca stresses are observed with the processing load depending on the number of nodes and elements. Figure 4 shows the result of the mesh sensitivity analysis. It can be seen that the stress values do not show any change with change in mesh size, which shows that the stress values are already converged in this range. So the selection of the mesh size is decided on the basis of the number of nodes and elements, i.e. is noted as $1.0 \mathrm{~mm}$. After this mesh size, there is an exponential rise in the number of nodes and elements, which will result in an increase of processor time and storage requirement without any difference in the accuracy of the stress results. Thus, to get a balanced performance, a mesh size of $1.0 \mathrm{~mm}$ is selected for meshing the model.

Table 1. Mechanical properties of titanium alloy BT9 [48].

\begin{tabular}{cccccc}
\hline Material & $\begin{array}{c}\text { Young's } \\
\text { Modulus }\end{array}$ & $\begin{array}{c}\text { Yield } \\
\text { stress } \\
{[52]}\end{array}$ & $\begin{array}{c}\text { Ultimate } \\
\text { tensile } \\
\text { strength [52] }\end{array}$ & $\begin{array}{c}\text { Cyclic strain } \\
\text { hardening } \\
\text { exponent, n }\end{array}$ & $\begin{array}{c}\text { Cyclic strength } \\
\text { coefficient, K' } \\
\text { [52] }\end{array}$ \\
\hline $\begin{array}{c}\text { Titanium } \\
\text { alloy BT9 }\end{array}$ & 118 & 910 & 1080 & $\begin{array}{c}\text { Stress-strain curve } \\
\text { (Fatemiet al. [48] }\end{array}$ \\
\hline
\end{tabular}

Table 2. Specimen and loads used for calibration for titanium alloy BT9.

\begin{tabular}{|c|c|c|c|c|}
\hline \multirow{2}{*}{ Specimen } & \multirow{2}{*}{ Load type } & \multicolumn{2}{|c|}{ Applied strain } & \multirow{2}{*}{ Cycles to failure [48] } \\
\hline & & Axial & Shear & \\
\hline Solid & Axial & 0.01 & --- & 960 \\
\hline \multirow{2}{*}{ Tubular } & Torsion & --- & 0.0173 & 498 \\
\hline & $90^{\circ}$ out-of-phase & 0.01 & 0.0173 & 142 \\
\hline
\end{tabular}


Table 3. Fatigue life for block loads with respect to each calibration for titanium alloy BT9.

\begin{tabular}{|c|c|c|c|c|c|c|c|c|}
\hline \multirow[b]{2}{*}{$\begin{array}{l}\text { Load } \\
\text { block }\end{array}$} & \multirow[b]{2}{*}{ Phase } & \multicolumn{2}{|c|}{ Applied strain } & \multirow[b]{2}{*}{ Cycles } & \multicolumn{4}{|c|}{ No. of blocks } \\
\hline & & Axial & Shear & & Experimental [48] & $\begin{array}{l}\text { Solid } \\
\text { axial }\end{array}$ & $\begin{array}{l}\text { Tubular } \\
\text { torsion }\end{array}$ & $\begin{array}{c}\text { Tubular } \\
\text { OOP }\end{array}$ \\
\hline \multirow[t]{2}{*}{ B1 } & --- & 0.01 & --- & 97 & 1 & 3.2 & 1.1 & 0.9 \\
\hline & --- & --- & 0.0173 & 301 & & & & \\
\hline \multirow[t]{2}{*}{ B2 } & --- & --- & 0.0173 & 398 & 1 & 2 & 0.7 & 0.57 \\
\hline & --- & 0.01 & --- & 205 & & & & \\
\hline \multirow[t]{2}{*}{ B3 } & --- & 0.01 & --- & 98 & 1 & 4.1 & 1.45 & 1.17 \\
\hline & 90 & 0.01 & 0.0173 & 86 & & & & \\
\hline \multirow[t]{2}{*}{ B4 } & 90 & 0.01 & 0.0173 & 80 & 1 & 2.1 & 0.66 & 0.55 \\
\hline & --- & --- & 0.0173 & 384 & & & & \\
\hline \multirow[t]{2}{*}{ B5 } & --- & --- & 0.0173 & 282 & 1 & 2.23 & 0.7 & 0.6 \\
\hline & 90 & 0.01 & 0.0173 & 108 & & & & \\
\hline \multirow[t]{2}{*}{ B6 } & 90 & 0.01 & 0.0173 & 61 & 1 & 5.8 & 2 & 1.65 \\
\hline & --- & 0.01 & --- & 70 & & & & \\
\hline \multirow[t]{2}{*}{$\mathrm{C} 1[53]$} & --- & 0.01 & --- & 40 & 2.5 & 7.5 & 2.6 & 2.11 \\
\hline & --- & --- & 0.0173 & 130 & & & & \\
\hline \multirow{2}{*}{$\mathrm{C} 1(2)$} & --- & 0.01 & --- & 65 & 1.8 & 4.5 & 1.55 & 1.27 \\
\hline & --- & --- & 0.0173 & 219 & & & & \\
\hline \multirow[t]{2}{*}{$\bar{C} 2[53]$} & --- & --- & 0.0173 & 176 & 1.9 & 5.1 & 1.8 & 1.46 \\
\hline & --- & 0.01 & --- & 66 & & & & \\
\hline \multirow[t]{2}{*}{$\mathrm{C} 2(2)$} & --- & --- & 0.0173 & 209 & 1.4 & 4.6 & 1.6 & 1.3 \\
\hline & --- & 0.01 & --- & 65 & & & & \\
\hline \multirow[t]{6}{*}{ C3 } & 90 & 0.010 & 0.0173 & 50 & 1.6 & 2.54 & 0.9 & 0.72 \\
\hline & --- & 0.01 & --- & 50 & & & & \\
\hline & --- & --- & 0.0173 & 50 & & & & \\
\hline & 90 & 0.01 & 0.0173 & 50 & & & & \\
\hline & --- & --- & 0.0173 & 50 & & & & \\
\hline & --- & 0.01 & --- & 50 & & & & \\
\hline
\end{tabular}

\section{Application of Proposed Model}

The titanium alloy BT9 specimen (Figure 2) is tested against block loads of axial, torsion and out-of-phase axial and torsion loading conditions published in the literature [48] (Table 2 and Table 3). The proposed model is developed using ANSYS internal programming language. The algorithm identifies the critical plane by identifying the plane with the maximum value of critical plane variable $\operatorname{crtpl}$ (Eq. (12)). The normal and shear stress and strain ranges $\left(\sigma_{\mathrm{n}, \max }, \tau_{\max }, \Delta \varepsilon, \Delta \gamma\right)$ with respect to the critical plane are calculated. Now, for the calibration loads (Table 2), for each set the calculated stresses and strains are used to determine the model parameters using GA procedures (MOGAII). The fatigue life value is calculated for the remaining loads other than used for calibration, using the proposed damage evolution equations (Eq.(8)- Eq.(10)). To implement this, code is developed in APDL which uses the model parameters calculated earlier and estimates the fatigue life for the current applied loading.

$$
\operatorname{crtpl}=\left(\Delta \gamma \cdot \tau_{\max }\right)+\left(\Delta \varepsilon \cdot \sigma_{n, \max }\right)
$$



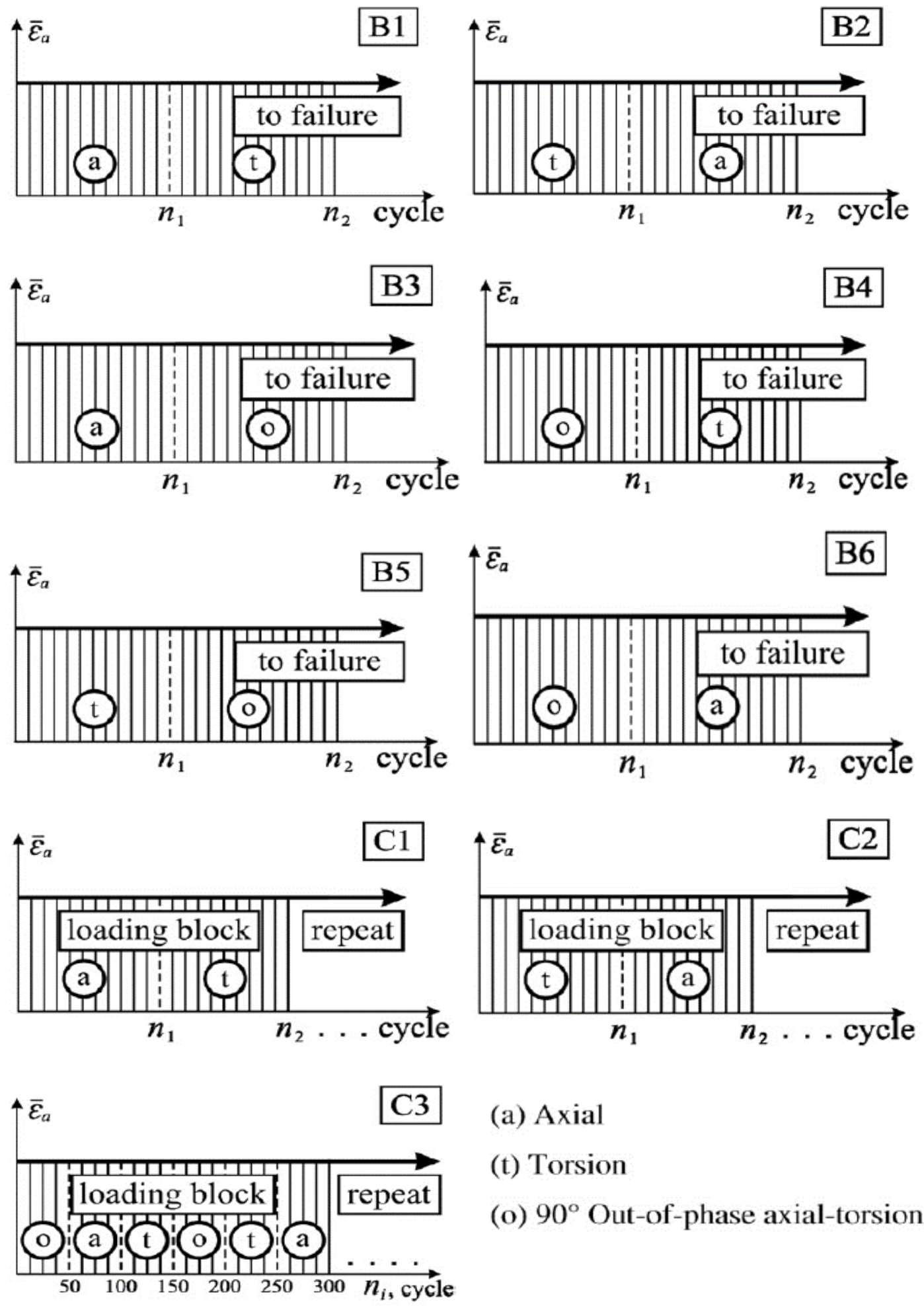

(a) Axial

(t) Torsion

(o) $90^{\circ}$ Out-of-phase axial-torsion

Figure 3. Loading blocks composed of different combinations of axial, torsion, and $90^{\circ}$ out-of-phase axial-torsion strain paths. 


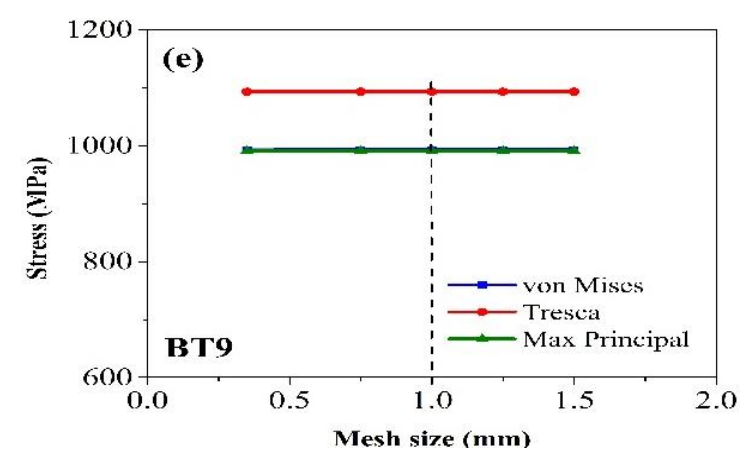

(a)

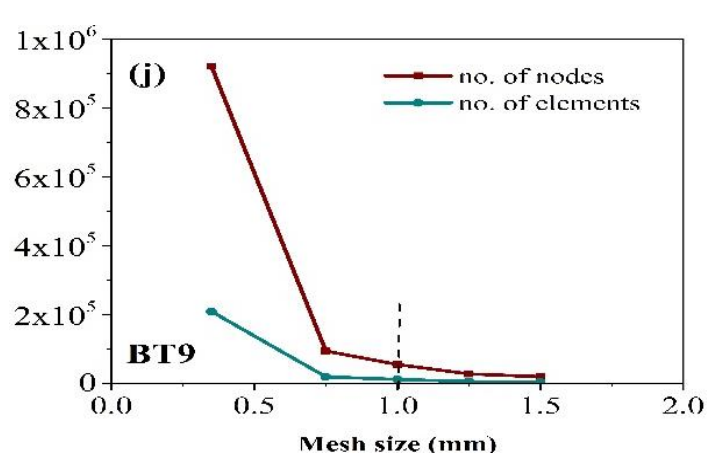

(b)

Figure 4. (a) Mesh size versus calculated FEA stresses, (b) Mesh size versus no. of nodes and elements of FEA model.

The proposed model is implemented by performing FEA to calculate the stressstrain state at the surface of the specimen at the centre of the gauge length, as this is the region most susceptible to failure. Then the stress components on the critical plane are calculated and the GA tool with Eq.(8)- Eq.(10) is used to determine the coefficients of the proposed model for fatigue life estimation. Fatigue life is predicted with three calibration loads (Table 2). Results from experimental fatigue life values from the literature (Table 3) [48] and predictions made by the proposed model are reported side by side in Table 3 and Figure 5.

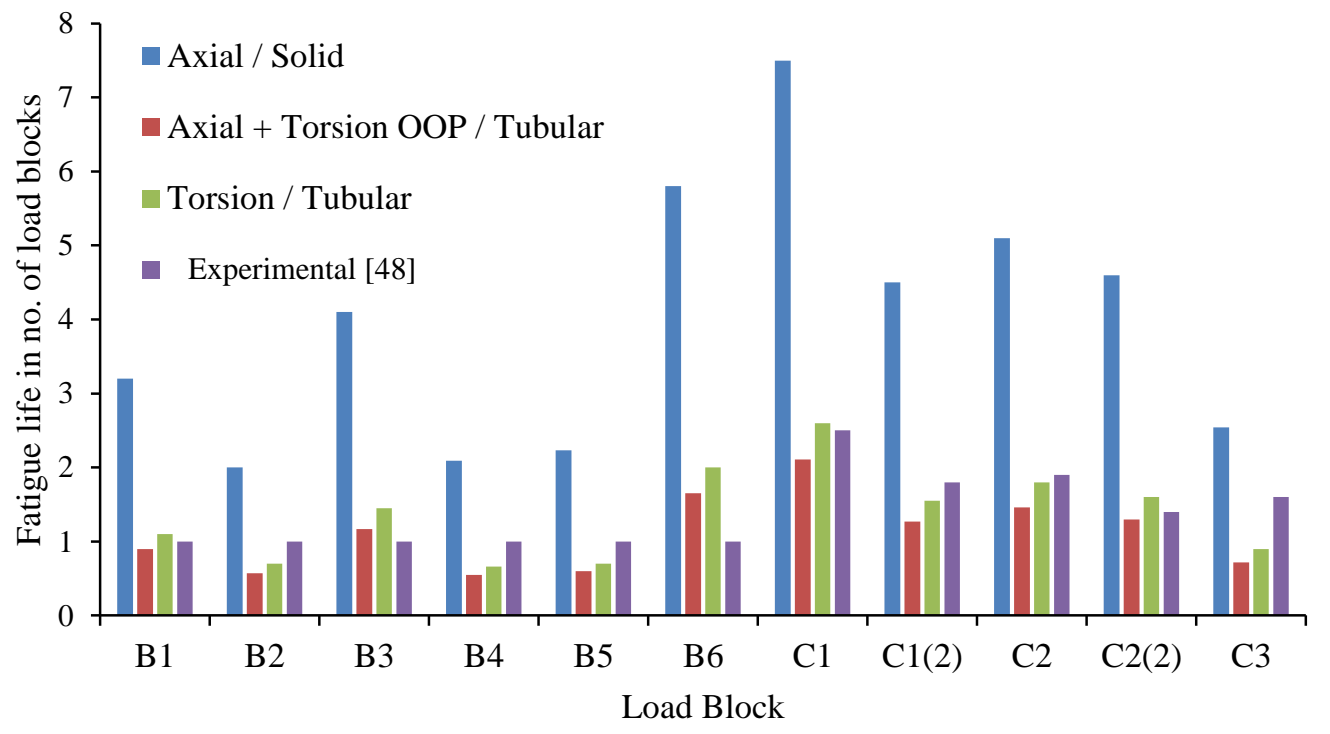

Figure 5. Predicted and experimental fatigue life for titanium alloy BT9 with applied normal and shear stress.

The block loading used for titanium alloy BT9 consists of axial, torsion and axialtorsion out-of-phase loading segments as shown in Figure 3 [48]. The proposed model is calibrated using the axial, torsion and axial-torsion out-of-phase loadings with the experimental fatigue life presented in Table 2. Calibrated coefficients from the axial loads are determined using the solid specimen, as the experimental fatigue life for the axial load is determined using a solid specimen [48]. The experimental fatigue life results for titanium alloy BT9 are given in Table 3, and were determined using the tubular specimen 
[48]. The predicted fatigue, along with the experimental fatigue lives for blocks of loading, are presented in Table 3. Block loading is considered in the form of load segments, with constant amplitude loading of magnitudes according to Table 3. For each block load, the critical plane is determined by evaluating the damage occurring in each segment of block load and then the cumulative damage is evaluated for each plane. The plane with the maximum damage is selected as the critical plane [48]. The stress-strain response of titanium alloy BT9 is not sensitive to the loading sequence and change in the strain path [48]. Thus, the fatigue life prediction is simplified by calculating the damage for each of the segments of block loads individually. The cumulative damage is then determined by summing up the individual load segments. Hence, the fatigue life is calculated in terms of the number of blocks required for failure.

From Table 3 it can be concluded that the concept of calibration of the proposed model from characteristic profiles, which are simpler than actual loading conditions but represent their behaviour, can be used in the case of fatigue life estimation of block loads. For the block loading considered in the study, blocks consisting of segments of constant amplitude loading with axial, torsion and out-of-phase axial-torsion profiles (Table 3) are used for fatigue life prediction when the proposed model is calibrated using axial, torsion and out-of-phase axial-torsion profiles, as mentioned in Table 2. A small error in the fatigue life estimation is expected, as the profiles used for calibration have only axial, torsion or out-of-phase axial-torsion load and the block loads have a mixture of the three load types (Figure 5). But still the predicted fatigue lives, i.e. the number of blocks to failure in the proposed model, are reasonably accurate, with a difference of 4-7\%, as shown in Figure 5. Any improvement in the profiles used for calibration which can better represent the characteristics of the block loads can further improve the accuracy of fatigue life prediction.

An important aspect related to the selection of the specimen geometry for calibration of the proposed model is identified from the fatigue life results (Table 3 ) in the case of calibrated coefficients from the axially loaded solid specimen. The fatigue life results from the axially loaded solid specimen show that the geometry of the specimen used for generating fatigue life data from experiments should either be similar in geometry or more precisely have a similar stress distribution to that in the component under study. The experimental fatigue life for the axially loaded specimen is determined by applying axial strain loads on the solid specimen [48], and torsion as well as out-ofphase loads are applied on the tubular specimen. Hence, the fatigue life results from the calibration performed by the axially loaded specimen resulted in non-conservative fatigue life results for all cases. From Table 3, B1 and B2, B3 and B6, and B4 and B5 are pairs of blocks that have similar segments but in the opposite order. Thus, the sequence effect is highlighted by examining the fatigue life results. For all cases the predicted fatigue life is within acceptable limits, where the coefficients calibrated by the hollow specimen with torsion and out-of-phase axial-torsion load are used as shown in Figure 5. With reference to the experimental observation by Fatemiet al. [48] that the material is not affected by the loading path, the damage predicted by the proposed model for each load segment is estimated separately and summed up to determine the total damage by the load block and thus the fatigue life as the number of load blocks. For loading blocks $\mathrm{C} 1$ and $\mathrm{C} 2$, the fatigue life predictions accuracy is better, which can be attributed to the number of cycles in the block segments. $\mathrm{C}$ series loading blocks have fewer cycles than B series loading blocks. As damage of the load segment is determined by multiplying the damage in one cycle by the number of cycles in that load segment, then the damage of each load segment is summed up to determine the total damage of the loading block. This can affect the 
accuracy of the fatigue life prediction when there are more cycles in the loading segment, because more cycles include more effects of previous loading cycles for the experimentally determined fatigue life. Hence it can be deduced that, to improve the accuracy of the proposed model and to better handle the sequence and damage accumulation effects, a full response history is required for fatigue life estimation. To reduce the size of the loading history, a filtered response history (with the most damaging cycles included) can also be an acceptable alternative to a full response history as, in general, approximately $10 \%$ of filtered histories can account for $90 \%$ of the total damage $[2]$.

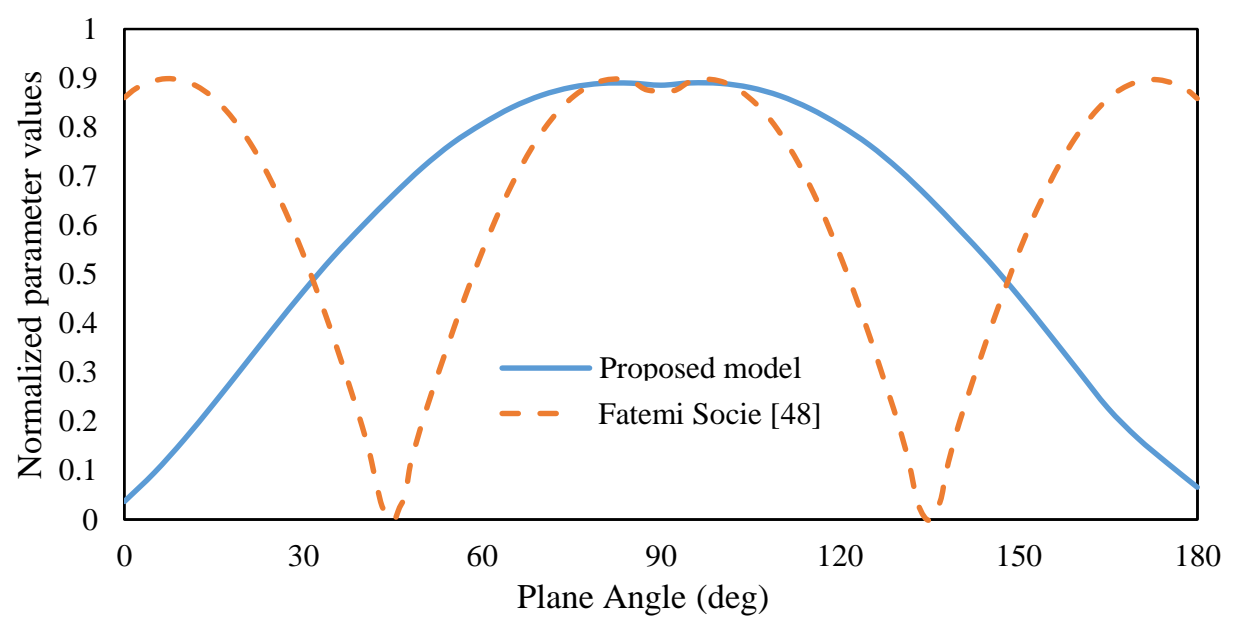

(a) Torsional loading

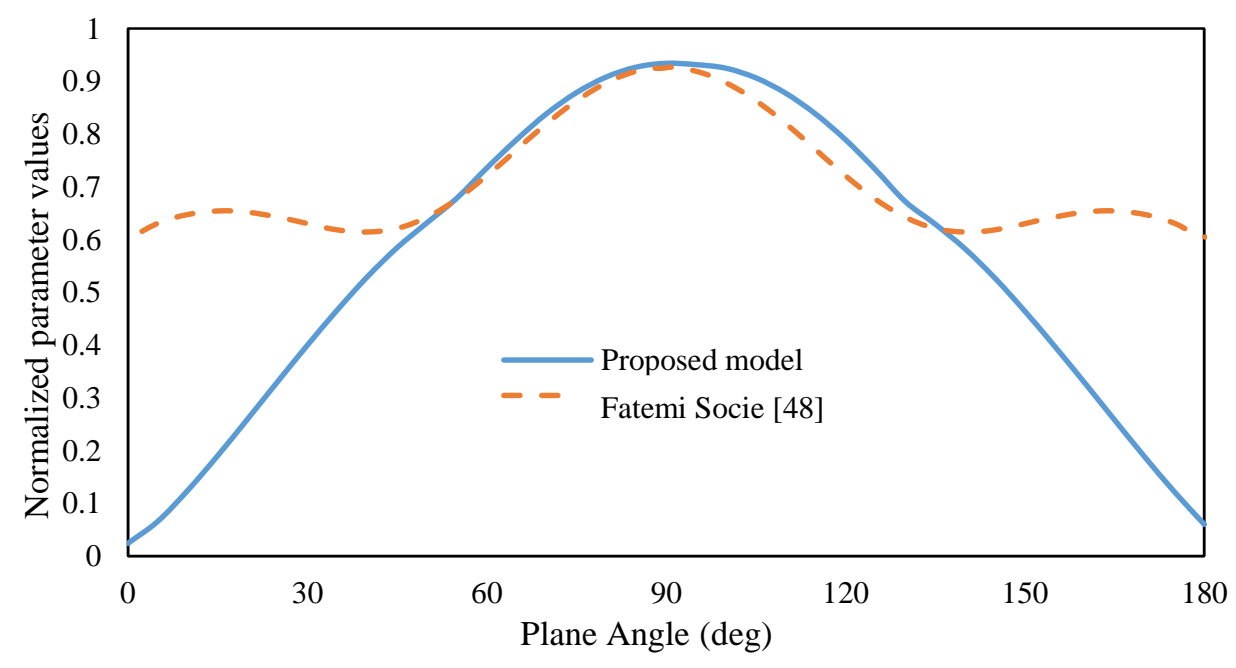

(b) Axial-torsional loading

Figure 6. Fatigue parameter variation for proposed and Fatemi-Socie model for titanium alloy BT9 with respect to plane angle.

Comparison of the variation of the proposed fatigue model parameter and the Fatemi-Socie model parameter [48] with respect to the plane angle is shown in Figure 6(a) for torsion loading and in Figure 6(b) for out-of-phase axial-torsion loading. The 
clear difference of trends in Figure 6 is due to the reliance of the proposed model parameter on normal and shear stress-strain to determine the parameter value, but in the case of the Fatemi-Socie model parameter, it follows the shear-strain range to locate the planes with the maximum value of strain range and then identify the critical plane among the located planes having the maximum normal stress [32]. In the case of out-of-phase axial-torsion load, the trend of the proposed model parameter has shown a clear peak to identify the critical plane, while the Fatemi-Socie model parameter has shown clear variation from the torsion case due to the applied axial load, but the identified plane is approximately the same, within $\pm 5^{\circ}$, as the proposed model parameter.

The critical planes orientations predicted by the proposed model parameter for block loads in Table 3 are presented in Figure 7, side by side with the orientations predicted by the Fatemi-Socie model parameter and observed experimentally [48]. By comparing the orientations of the critical plane with the experimental data as shown in Figure 7, the proposed model predicted the critical plane orientation within approximately $\pm 10^{\circ}$, which is also similar to the accuracy of the predictions made by the Fatemi-Socie model. Thus the proposed model is able to predict the location of the critical plane and fatigue life with reasonable accuracy for block loading, even with the assumptions made to simplify the analysis by assuming that block loads consist of segments and the damage to each segment is calculated with reference to the damage done in one cycle in that segment. The accuracy of the proposed model can be further improved by applying the block loading as a full or filtered profile so that only high damage cycles remain and the sequence effect of previous loading cycles can be captured.

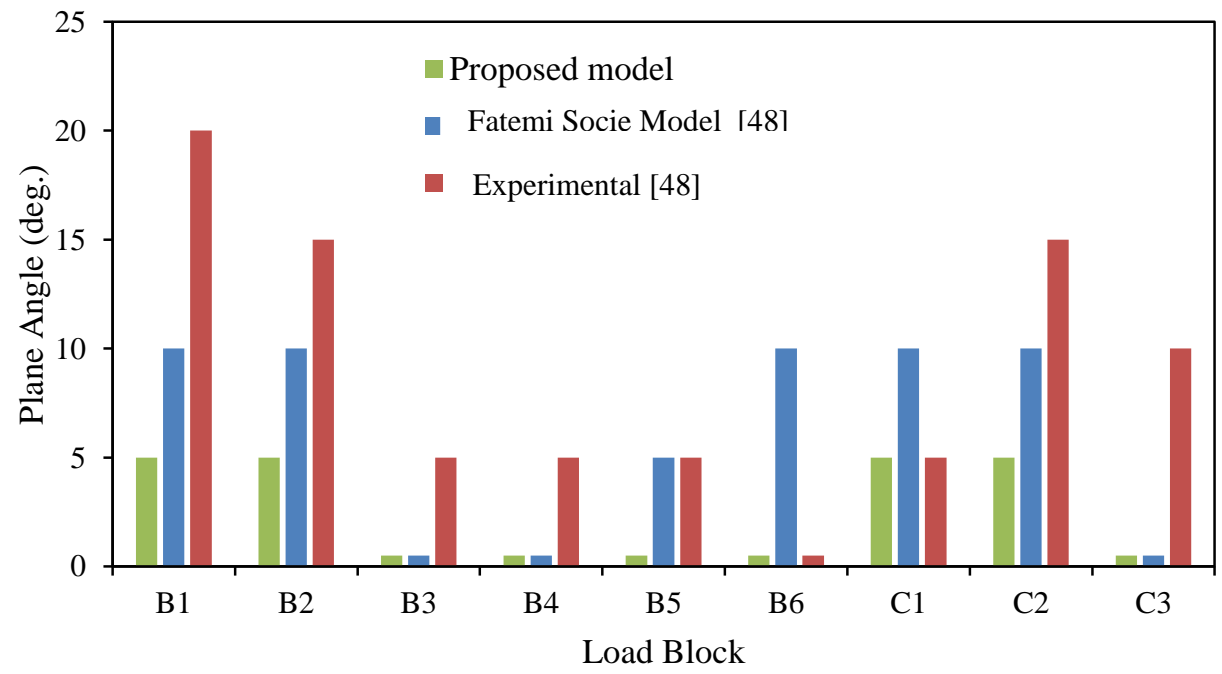

Figure 7. Critical plane orientation for each block loading by proposed model, FatemiSocie model and experimentally determined for titanium alloy BT9.

\section{CONCLUSIONS}

A new fatigue life estimation model has been proposed using the continuum mechanics concepts. Experimental fatigue lives for titanium alloy BT9 for axial, torsion and out-ofphase axial-torsion block loading conditions are used to calibrate and analyse the accuracy of the proposed model. The new model predicted fatigue life with good accuracy for the block loads calibrated with torsion and out-of-phase axial and torsion load profiles. The difference observed in the experimental and fatigue life in the case of block loads is 
mainly due to the difference of specimen geometry, as well as the fact that the axial, torsion and out-of-phase profiles are only used for coefficient calibration to estimate the fatigue life for block loads. Generally, the model has shown good accuracy and is simple to apply. A more detailed study is needed to study the effect of the characteristic profile used for calibration for block loads, to represent the stress-strain behaviour of the applied block load more accurately.

\section{ACKNOWLEDGMENTS}

The authors would like to thank Universiti Malaysia Pahang for financial support under project no. RDU130146 and Postgraduate Research grant scheme (GRS140309) and providing laboratory facilities.

\section{REFERENCES}

[1] Lee Y, Pan J, Hathaway R, Barkey M. Fatigue testing and analysis: Theory and practice. New York: Butterworth Heinemann; 2005.

[2] Stephens RI, Fatemi A, Stephens RR, Fuchs HO. Metal fatigue in engineering. New York: John Wiley and Sons, Inc.; 2000.

[3] Manson SS, Halford GR. Fatigue and durability of structural materials. Materials Park, Ohio: ASM International, Materials; 2006.

[4] Papuga J. A survey on evaluating the fatigue limit under multiaxial loading. International Journal of Fatigue. 2011;33:153-65.

[5] Fatemi A, Shamsaei N. Multiaxial fatigue: An overview and some approximation models for life estimation. International Journal of Fatigue. 2011;33:948-58.

[6] Brighenti R, Carpinteri A. A notch multiaxial fatigue approach based on damage mechanics. International Journal of Fatigue. 2012;39:122-33.

[7] Rahman MM, Kadirgama K, Noor MM, Rejab MRM, Kesulai SA. Fatigue life prediction of lower suspension arm using strain-life approach. European Journal of Scientific Research. 2009;30:437-50.

[8] Beden SM, Abdullah S, Ariffin AK, Al-Asady NA, Rahman MM. Fatigue life assessment of different steel-based shell materials under variable amplitude loading. European Journal of Scientific Research. 2009;29:157-69.

[9] Rahman MM, Bakar RA, Noor MM, Rejab MRM, Sani MSM. Fatigue life prediction of spot-welded structures: A finite element analysis approach. European Journal of Scientific Research. 2008;22:444-56.

[10] Abdullah S, Beden SM, Ariffin AK, Rahman MM. Fatigue life assessment for metallic structure: A case study of shell structure under variable amplitude loading. Journal of Applied Sciences. 2008;8:1622-31.

[11] Rahman MM, Ariffin AK, Jamaludin N, Haron CHC. Influence of surface treatments on fatigue life of a two-stroke free piston linear engine component using random loading. Journal of Zhejiang University: Science. 2006;7:1819-30.

[12] Susmel L, Taylor D. The modified wohler curve method applied along with the theory of critical distances to estimate finite life of notched components subjected to complex multiaxial loading paths. Fatigue and Fracture of Engineering Materials and Structures. 2008;31:1047-64.

[13] Atzori B, Berto F, Lazzarin P, Quaresimin M. Multi-axial fatigue behaviour of a severely notched carbon steel. International Journal of Fatigue. 2006;28:485-93. 
[14] Susmel L, Taylor D. A critical distance/plane method to estimate finite life of notched components under variable amplitude uniaxial/multiaxial fatigue loading. International Journal of Fatigue. 2012;38:7-24.

[15] Susmel L, Tovo R. Estimating fatigue damage under variable amplitude multiaxial fatigue loading. Fatigue \& Fracture of Engineering Materials \& Structures. 2011;34:1053-77.

[16] Bishop NWM, Sherratt F. Finite element based fatigue calculations. Netherlands: NAFEMS Ltd.; 2000.

[17] Rahman MM, Ariffin AK, Rejab MRM, Kadirgama K, Noor MM. Multiaxial fatigue behaviour of cylinder head for a free piston linear engine. Journal of Applied Sciences. 2009;9:2725-34.

[18] Kamal M, Rahman MM. Multiaxial fatigue life modelling using hybrid approach of critical plane and genetic algorithm. Fatigue and Fracture of Engineering Materials and Structures. 2016;39:479-90.

[19] Kaamal M, Rahman MM. Dual-criteria method for determining critical plane orientation for multiaxial fatigue prediction using a genetic algorithm. International Journal of Automotive and Mechanical Engineering. 2015;11:257181.

[20] Rahman MM, Ariffin AK, Rejab MRM, Kadirgama K, Noor MM. Multiaxial fatigue behavior of cylinder head for a free piston linear engine. Journal of Applied Sciences. 2009;9:2725-34.

[21] Mohamed SAN, Abdullah S, Arifin A, Ariffin AK, Padzi MM. Characterization of the biaxial fatigue behaviour on medium carbon steel using the strain-life approach. International Journal of Automotive and Mechanical Engineering. 2016;13:3262-77.

[22] Ismail AE. Mode i stress intensity factors of sickle-shaped surface cracks in round solid bars under bending moment. International Journal of Automotive and Mechanical Engineering. 2016;13:3329-44.

[23] Abdul Majid MS, Daud R, Afendi M, Amin NAM, Cheng EM, Gibson AG, et al. Stress-strain response modelling of glass fibre reinforced epoxy composite pipes under multiaxial loadings. Journal of Mechanical Engineering and Sciences. 2014;6:916-28.

[24] Rahman MM, Ariffin AK, Jamaludin N, Haron CHC. Vibration fatigue analysis of cylinder head of a new two-stroke free piston engine using finite element approach. Structural Integrity and Durability. 2005;1:121-9.

[25] Kamal M, Rahman MM. Fatigue life estimation based on continuum mechanics theory with application of genetic algorithm. International Journal of Automotive and Mechanical Engineering. 2015;11:2686-98.

[26] Kamal M, Rahman MM. An integrated approach for fatigue life estimation based on continuum mechanics theory and genetic algorithm. International Journal of Automotive and Mechanical Engineering. 2015;11:2756-70.

[27] Kamal M, Rahman MM. Fatigue life estimation models: A state of the art. International Journal of Automotive and Mechanical Engineering. 2014;9:1599608.

[28] Kamal M, Rahman MM. Finite element-based fatigue behaviour of springs in automobile suspension. International Journal of Automotive and Mechanical Engineering. 2014;10:1910-9.

[29] Ottosen NS, Stenstrom R, Ristinmaa M. Continuum approach to high-cycle fatigue modeling. International Journal of Fatigue. 2008;30:996-1006. 
[30] Nieslony A, Ruzicka M, Papuga J, Hodr A, Balda M, Svoboda J. Fatigue life prediction for broad-band multiaxial loading with various psd curve shapes. International Journal of Fatigue. 2012;44:74-88.

[31] Socie DF, Marquis GB. Multiaixal fatigue. Warrendale, PA, USA: SAE; 2000.

[32] Fatemi A, Socie DF. A critical plane approach to multiaxial fatigue damage including out of phase loading. Fatgiue and Fracture of Engineering Materials and Structures. 1988;11:149-66.

[33] Wang $\mathrm{CH}$, Brown MW. A path independent parameter for fatigue under proportional and non proportional loading. Fatigue and Fracture of Engineering Materials and Structures. 1993;16:1285-98.

[34] Brown MW, Miller KJ. Two decades of progress in the assessment of multiaxial low-cycle fatigue life. In: Amzallag C, Leis BN, Rabbe P, editors. Low-cycle fatigue and life prediction. West Conshohocken, PA: American Society for Testing and Materials; 1982. p. 482-99.

[35] Smith KN, Watson P, Topper TH. A stress-strain function for the fatigue of metals. Journal of Materials. 1970;5:767-78.

[36] Ince A, Glinka G. A modification of morrow and smith-watson-topper mean stress correction models. Fatigue and Fracture of Engineering Materials and Structures. 2011;34:854-67.

[37] Li J, Sun Q, Zhang ZP, Li CW, Zhang DW. A new multiaxial fatigue life prediction model under proportional and nonproportional loading. Journal of Engineering Materials and Technology. 2010;132:pp.8.

[38] Li J, Zhang ZP, Sun Q, Li CW. Multiaxial fatigue life prediction for various metallic materials based on the critical plane approach. International Journal of Fatigue. 2011;33:90-101.

[39] Shang D-G, Sun G-Q, Bao M. Multiaxial fatigue damage parameter and life prediction under low cycle loading for gh4169 alloy and other structural materials. International Journal of Fatigue. 2010;32:1108-15.

[40] Ince A, Glinka G. A generalized fatigue damage parameter for multiaxial fatigue life prediction under proportional and non-proportional loadings. International Journal of Fatigue. 2014;62:34-41.

[41] Davis L. Handbook of genetic algorithms. New York: Van Nostrand Reinhold; 1991.

[42] Whitely D. A genetic algorithm tutorial. Statistics and Computing. 1994;4:65-85.

[43] Clarich A, Russo R, Carriglio M. Multi-objective optimization with modefrontier interfaces for ansa and metapost. 4th ANSA \& $\mu$ ETA International Conference. Thessaloniki, Greece2011. p. pp. 1-16.

[44] Perillo M, Primavera V, Fuligno L, Fabbri G, Steenbergen C, Pasini N. Optimization and robustness of complex material model simulations with modefrontier. In: 7th European LS-DYNA Conference. Salzburg, Austria; 2009. p. pp. 1-10.

[45] Franulovic M, Basan R, Prebil I. Genetic algorithm in material model parameters' identification for low-cycle fatigue. Computational Materials Science. 2009;45:505-10.

[46] Gantovnik VB, Anderson-Cook CM, Gürdal Z, Watson LT. A genetic algorithmwith memory for mixed discrete-continuous design optimization. Computer and Structures. 2003;81:2003-9. 
[47] Brighenti R, Carpinteri A, Vantadori S. A genetic algorithm applied to optimisation of patch repairs for cracked plates. Computer Methods in Applied Mechanics and Engineering. 2006;196:466-75.

[48] Fatemi A, Shamsaei N, Gladskyi M, Panasovskyi K, Shukaev S. Multiaxial fatigue of titanium including step loading and load path alteration and sequence effects. International Journal of Fatigue. 2010;32:1862-74.

[49] Kamal M, Rahman MM, Sani MSM. Fatigue life prediction using simplified endurance function model. Advances in Mechanical Engineering. 2013;2013:pp. 12.

[50] Kamal M, Rahman MM, Rahman AG. Fatigue life evaluation of suspension knuckle using multi body simulation technique. Journal of Mechanical Engineering and Sciences. 2012;3:291-300.

[51] Rahman MM, Ariffin AK, Abdullah S, Noor MM, Bakar RA. Durability assessment of cylinder block for two stroke free piston linear engine using random loading. American Journal of Applied Sciences. 2009;6:726-35.

[52] Bhaskar K, Nagarajan G, Sampath S. Experimental investigation on cold start emissions using electrically heated catalyst in a spark ignition engine. International Journal of Automotive and Mechanical Engineering. 2010;2:105-18.

[53] Guo Y, Xu W, Fu Y, Zhang W. Comparison studies on dynamic packaging properties of corrugated paperboard pads. Engineering. 2010;2:378-386. 